\title{
Measurement errors in cirrus cloud microphysical properties
}

\author{
H. Larsen ${ }^{1}$, J.-F. Gayet ${ }^{2}$, G. Febvre ${ }^{2}$, H. Chepfer ${ }^{3}$ and G. Brogniez ${ }^{3}$ \\ ${ }^{1}$ National Institute for Water and Atmosphere, Wellington, New Zealand \\ ${ }^{2}$ Laboratoire de Métérologie Physique, UPRESA/CNRS n6016, Université Blaise Pascal, Clermont-Ferrand, France \\ ${ }^{3}$ Laboratoire d'Optique Atmosphérique, URA CNRS 713, Université des Sciences et Technologies de Lille, France
}

Received: 12 April 1996 / Revised: 13 June 1997 / Accepted: 21 July 1997

\begin{abstract}
The limited accuracy of current cloud microphysics sensors used in cirrus cloud studies imposes limitations on the use of the data to examine the cloud's broadband radiative behaviour, an important element of the global energy balance. We review the limitations of the instruments, PMS probes, most widely used for measuring the microphysical structure of cirrus clouds and show the effect of these limitations on descriptions of the cloud radiative properties. The analysis is applied to measurements made as part of the European Cloud and Radiation Experiment (EUCREX) to determine mid-latitude cirrus microphysical and radiative properties.
\end{abstract}

Key words Atmospheric composition and structure (cloud physics and chemistry) - Meteorology and atmospheric dynamics $\cdot$ Radiative processes $\cdot$ Instruments and techniques

\section{Introduction}

The understanding and modelling of climate processes is a critical global issue, and problems involving cirrus clouds are amongst the most immediate. Cirrus clouds are important determinants of the climate, modulating both the input of energy to the climate system and the output of energy from it (e.g. Ramanathan et al., 1983, 1989) over a large area of the globe at any one time (Bretherton and Suomi, 1983). Their impact on the global radiation balance and their consequent involvement in feedback processes will be determined by their areal coverage, their temperature and by the way they interact with both incoming short wave (solar) and outgoing long wave (terrestrial) radiation. This broadband radiative behaviour is in turn determined by the

Correspondence to: J.-F. Gayet cloud microphysical properties (Stephens et al., 1990; Heymsfield, 1993). It is determined by how many cloud particles there are, how much radiant energy they intercept and emit, and how this energy is distributed in space and in wavelength. Modelling the cloud radiative behaviour requires a knowledge of the total water substance in the cloud, the number concentration of cloud particles and their size distribution, their cross section for the interception of radiation (related to their projected geometric cross section and hence their shape and size) and their scattering phase functions (also determined by the particle shape, and its phase, water or ice).

However there have been only a limited number of detailed observations of the cirrus cloud microphysical properties needed in modelling the interaction of the cirrus with radiation. What measurements there are indicate there can be a wide range of ice water content, cloud depth, and ice crystal shapes, sizes and concentration, making these clouds difficult to parametrise (Stephens et al., 1990; Ramanathan et al., 1995). They are thus poorly represented in current climate models. The measurements have tended to be in mid-latitude non-convective clouds formed by large-scale ascent. Additional in situ measurements of cirrus cloud microphysical properties are needed, particularly of contrailinduced cirrus, tropical cirrus, Southern Hemisphere cirrus and cirrus formed by convective processes, to improve the modelling of cirrus in climate processes. At the same time there are limitations on the measurements that are currently available or that can be made with currently available instruments. We will show here that this means these measurements could mislead the modelling work, if not applied with great care. An additional concern is that these measurements, being made in situ, may be treated as 'absolute' measurements and used to calibrate remote sensing instruments without regard for their limitations.

We first describe the measurement probes and their limitations, then consider the radiative implications. There are radiative implications of the limitations on the 
measurement of particle shape, on the detection of small particles and on the determination of integrated measures of cloud water. These implications are demonstrated through analysis of measurements made as part of the field phase observations within the European Cloud and Radiation Experiment (EUCREX). These observations were made in several areas in Western Europe to determine mid-latitude cirrus microphysical and radiative properties (Raschke, 1996).

\section{PMS probes}

Most available in situ cirrus microphysics measurements have been made using aircraft-borne optical imaging or scattering probes, commercially available PMS 2D-C and PMS FSSP-100 respectively (Knollenberg, 1976). There are a limited number of measurements on ice crystals captured on replicators (e.g. Cooper and Vali, 1981; Heymsfield, 1986) and new instruments are now coming into use: the counterflow virtual impactor or CVI (Ström and Heintzenberg, 1994), an advanced replicator (Strauss et al., 1995), holographic cloud particle imaging systems (Brown, 1989; Lawson, 1995), an evaporative technique for total water measurements (Nicholls et al., 1990), the video ice particle sampler (McFarquhar and Heymsfield, 1996) and a polar nephelometer (Gayet et al., 1997; Crépel et al., 1997). There are also less widely used PMS probes (FSSP-300, 260X-1D-C, 2D-Grey, 2D2-P) which can be used to extend the data available and so overcome some of the limitations of the other probes. For the moment the alternatives offer a check on the PMS 2D-C and PMS FSSP-100 data rather than a useful database on cirrus microphysics in their own right.

During EUCREX some CVI, advanced replicator, holographic and total water measurements were available but the vast bulk of the data are from the PMS 2D$\mathrm{C}$ and PMS FSSP-100. Thus, users of EUCREX data in particular should realise that unless otherwise indicated the data has the limitations described.

\subsection{PMS 2D-C probe}

The data from these probes are recorded as two dimensional images of individual cloud particles, sometimes several hundred per second, passing through the sampling volume of the instrument. Typically the probe covers a particle size range of $25-800 \mu \mathrm{m}$ with a pixel size of $25 \mu \mathrm{m}$. The analysis techniques use specific algorithms applied to the image of each particle to identify that particle's shape and size (Heymsfield and Parrish, 1978; Duroure, 1982; Heymsfield and Baumgardner, 1985; Duroure et al., 1994; Fouilloux et al., 1997) and to determine particle concentration.

The accuracy and consistency of the 2D-C probes has been examined (Gayet et al., 1993) as part of the ICE/ EUCREX programme to determine cirrus microphysical properties. Although development and use of the $2 \mathrm{D}-\mathrm{C}$ probe unquestionably represents a great advance in cloud physics instrumentation, inherent probe and data analysis shortcomings limit the conditions under which the data can be relied on. There are four problems in particular, related to: (1) the determination of the absolute particle number concentration, (2) the identification of particle shape, (3) the limited range of sizes of particles over which the measurements can be made and (4) the limited sample volume of the probes.

The first problem, in determining the absolute number concentration, comes from three sources. The major one relates to the data handling in different probes. Figure 1 shows the size spectra obtained simultaneously from three 2D-C probes mounted close together on the same aircraft during a flight in cirrostratus at a temperature of around $-35^{\circ} \mathrm{C}$ (Gayet et al., 1993). The probes show large differences in particle concentration for the larger sizes, even although measuring closely spaced volumes of the same cloud. The differences appear to be due to instrumentation problems rather than true cloud differences (Gayet et al., 1993), and are related particularly to the probe version being used, with the updated 2D2-C version apparently detecting some $50 \%$ more images than the original version 2D-C. The second source of concentration measurement problems arises through the poor definition of the sampling volume, associated with response time problems. This would be expected to affect primarily the smaller size channels $(25-100 \mu \mathrm{m})$, causing a greater degree of undercounting of small particles than larger particles, as shown theoretically by Baumgardner et al. (1986) and Baumgardner (1987). These authors proposed airspeed corrections on size and sample volume which should adequately account for electronic response-time problems, but these corrections are often not applied, the investigators being unfamiliar with the probes and their limitations. The third concentration measurement problem arises in the software used for

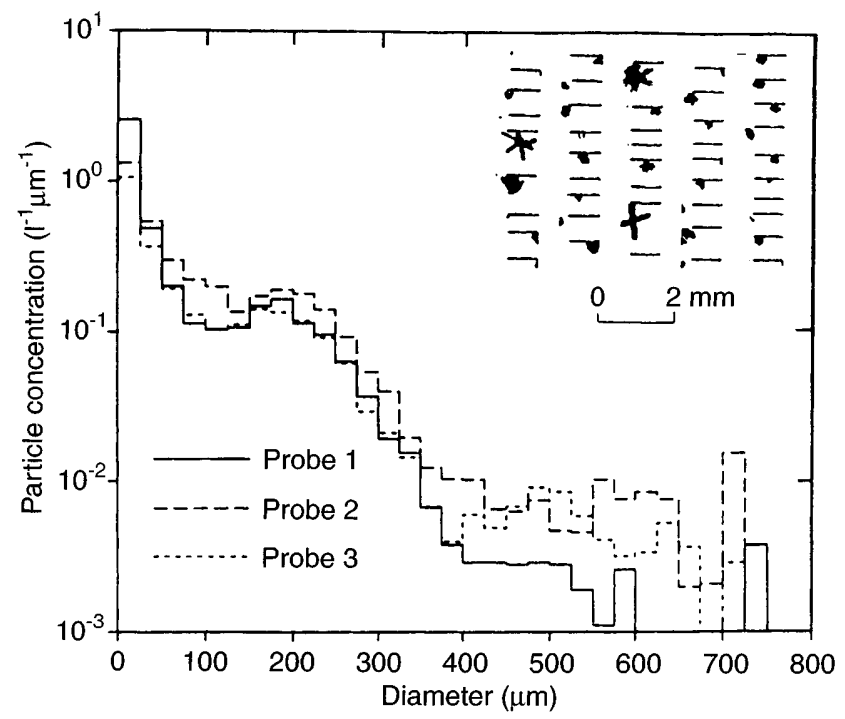

Fig. 1. Particle-size spectra obtained from simultaneous measurements by three different PMS 2D-C probes for a 2-mn segment in a cirrostratus cloud. An example of corresponding sample ice-crystal habits is shown in the upper-right of the figure 


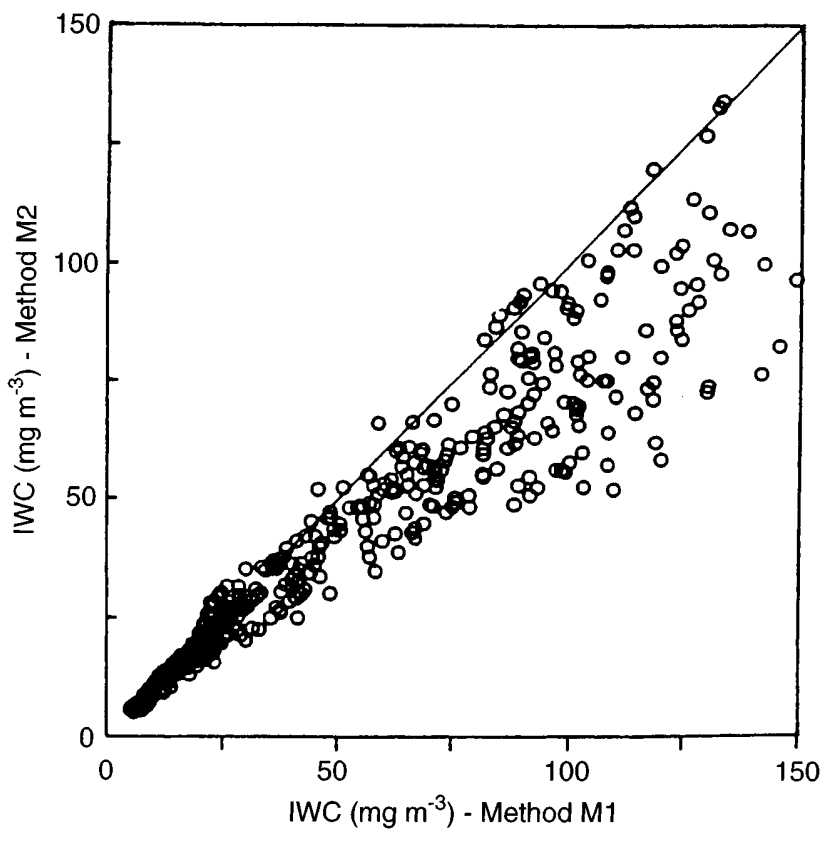

Fig. 2. Comparison of the ice water content $(I W C)$ obtained from two methods of data processing (M1, M2) applied to a same data set (cirrus measurements performed near $-30^{\circ} \mathrm{C}$ during mission 210 of the International Cirrus Experiment ICE/EUCREX)

data analysis. Figure 2 illustrates the differences in the ice water content $(I W C)$ determined by using two different methods of data processing which have been used at various times by different groups (Gayet et al., 1990), here applied to the same data set (cirrus measurements performed at around $-30^{\circ} \mathrm{C}$ ). The methods differ in the way the sampling time is calculated. The differences lead to relative errors of up to $50 \%$, suggesting the need for the development of a common processing scheme in order to reduce the uncertainties in results. It also illustrates the care is necessary when comparing measurements made during multi-aircraft experiments. (Details of the derivation of $I W C$ from 2D$\mathrm{C}$ probe data can be found in the Appendix)

The second problem with the 2D-C relates to shape measurement (e.g. Duroure et al., 1994). The techniques of data analysis involve intensive computer use but even so, are able to identify reliably only relatively regular crystal shapes. In practice a large natural variability in crystal shapes is often found (due to the presence of spatial dendrites, or aggregates, for example). In such cases a large percentage of the particles are classified simply as 'irregular'. Their shapes, and hence their optical properties and their mass are not adequately determined as a function of size, and their contribution to the derived cloud parameters cannot be evaluated and may be neglected. Recent work by Fouilloux et al. (1997) offers some improvement in shape analysis.

The third problem is that the range of sizes of particles for which the shapes and sizes can be reliably registered by the PMS probes is very limited, because of the low resolution (the image space is only 32 pixels wide) and the optical distortions of the probes due to diffraction and partial transmission (Korolev et al., 1991). Particle shape recognition is unreliable for ice crystals less than about $100 \mu \mathrm{m}$ maximum dimension, as this represents typically only four image pixels for this probe. It is also unreliable for particles which overlap an edge of the image area (giving a truncated image), either because the particles are too large for the 32 pixel wide imaged area or because they passed through the probe sampling volume near its edges. In many cases these images are simply rejected in the analysis. In order to minimize the subsequent size limitation effects, Heymsfield and Parrish (1978) proposed a computational technique which increases the sampling volume and size range of the instrument when the particles can be assumed to be spherical, by estimating the true size from the partial images, but the range remains limited. In the mid-latitude non-convective cirrus studied during EUCREX very few particles larger than the size range of the 2D-C were found and as we will see in Sect. 4 and 5.2, much larger errors arise from the lack of reliable measurements of small ice particles in the size range 1$50 \mu \mathrm{m}$. Studies of anvil-induced cirrus or tropical convectively-formed cirrus on the other hand need measurements of larger precipitating ice particles because the considerable mass carried by those particles, as reported by Heymsfield (1986) and Heymsfield et al. (1990). In this case other instruments such as the PMS 2D-P (nominal size range $0.2 \mathrm{~mm}-6.4 \mathrm{~mm}$ ) must be used to extend the range of the 2D-C.

The fourth problem with the $2 \mathrm{D}-\mathrm{C}$ relates to its limited sample volume, which results in particles which have a low concentration (typically the largest particles) being poorly sampled. The technique of Heymsfield and Parrish (1978) significantly extends the sample volume. However in situations where larger precipitating particles are present they are still not likely to be adequately sampled and a probe with a larger sampling volume (and size range), such as the 2D-P, must be used.

Some of the problems noted can be minimised by careful use. Nevertheless Moss and Johnson (1992), considering the data from a total of 11 flights in cloud, found that their analysis algorithms rejected an average of $77 \%$ of particle images, and they based their assessment of cloud microphysical properties on the remaining $23 \%$ of images. Considering that many of these rejected images will have been rejected by the analysis algorithms precisely because the particles they depict are not like those in the images accepted, the danger in accepting the $23 \%$ as representative of the cloud is apparent. This limitation affects the confidence which can be placed in both the description of particle shapes present, and the estimates of size - integrated quantities such as ice water content. While recent analysis techniques offer some improvement (Duroure et al., 1994; Fouilloux et al., 1997), the accuracy of estimates of derived quantities sensitive to particle shape, such as radiative parameters and mass-integral quantities, remains limited. 


\subsection{PMS FSSP-100 probe}

The FSSP-100 probe operates by measuring directly the light scattering properties of each particle, integrated over a narrow range of angles. It has proved an excellent instrument for measuring spherical water droplets in an all-water cloud (e.g. Cerni, 1983).

In the absence of any other more reliable instrument working in this range of particle size, the FSSP-100 has also been used for the detection of small ice crystals, rather than water drops, in support of the interpretation of cirrus radiative properties (Platt et al., 1989; Heymsfield and McFarquhar, 1996). However Vali et al. (1980), Gardiner and Hallett (1985), and others since, found that the FSSP-100 is highly unreliable for the counting and sizing of small ice crystals and for droplets in the presence of ice crystals. Their data indicated that the number concentrations in FSSP-measured size spectra may be erroneously enhanced 1 to 2 orders of magnitude by the presence of ice particles. It is presumed that the overcounting is generated by ice particles outside the normal sampling volume of the instrument, which because of their shape are able to generate scattering signals mimicking those of particles within the sampling volume. Only under very specific conditions when all the ice is in the form of small quasispherical particles, such as in cirrus formed from recently generated aircraft contrails, does the FSSP probe appear to give reliable measurements in clouds containing ice (Gayet et al., 1996 a).

Therefore, unless there is independent evidence that the ice particles are spherical, FSSP-100 measurements of smaller particles in cirrus should not be relied on.

Some of the new instruments have been developed specifically to provide more reliable small ice crystal measurements: the video ice particle sampler (VISP, McFarquhar and Heymsfield, 1996) and the advanced replicator (Strauss et al., 1995) can both provide images of particles as small as $5 \mu \mathrm{m}$ and the polar nephelometer can measure optical and microphysical parameters of particles down to about $1 \mu \mathrm{m}$ (Gayet et al., 1997; Crépel et al., 1997). The recently developed PMS FSSP-300 also may be reliable in ice crystal clouds when the particles are small (Heymsfield and Miloshevich, 1995).

\section{Particle shape and cloud radiative properties}

\subsection{Radiative transfer calculations}

We now consider the radiative implications of the limitations on the measurement of particle shape noted already. The cloud albedo calculations are made using Zdunkowski's method (1980). We assume the cirrus cloud is over sea which has a reflectivity of 0.05 ; the aerosol distribution between the cloud and sea is continental (WCRP, 1986); and that scattering has no effect on the cloud infra-red emissivity. These assumptions are appropriate for the mid-latitude nonconvective cirrus measured over the North Sea during EUCREX.
The cloud albedo, which determines the amount of solar radiation reflected back to space from the cloud, is dependent on the scattering properties (generally expressed as the scattering phase functions) of the individual cloud particles, in turn dependent on their shape. The emissivity (which determines the cloud interactions with long wave terrestrial radiation) is also affected by particle shape, but less so particularly as the particle size approaches the wavelength.

It is difficult to model the radiative scattering from complex shaped ice crystals. For water clouds, with spherical droplets, the scattering phase function can be determined from Mie theory but there is as yet no equivalent theory for scattering from ice crystals. Nevertheless, scattering by simple shaped (hexagonal) and bullet-rosette ice crystals has been computed (e.g. Brogniez, 1988; Takano and Liou, 1989; Iaquinta et al., 1995 ) by using ray tracing techniques in order to generate scattering phase function for arbitrary orientations.

\subsection{Simple-shaped ice crystals}

Calculations of cloud albedo and emissivity using the special cases of spherical, simple hexagonal column and simple hexagonal plate shapes are sufficient to indicate the sensitivity to the non-sphericity of the cloud particles. Figure 3 a shows the calculated cloud albedo as a function of the solar zenith angle at a wavelength of $0.55 \mu \mathrm{m}$ and for these three simple geometrical shapes of particles assuming a constant ice water content over all the cloud depth. For a given solar zenith angle the albedo of an extended cloud calculated for a cloud of ice sphere particles is seen to be around twice as high as for a cloud of ice column or plate particles. Substantially larger differences are found for the calculated infra-red emissivity of the clouds, at a wavelength of $11 \mu \mathrm{m}$ (Fig. $3 b)$. The infra-red emissivity for a cloud of ice sphere is three times greater than for one of column particles.

\subsection{Irregular particles}

The in-situ measurements show most cirrus particles are irregular, at least in 2-D projection (e.g. Moss and Johnson, 1992). The scattering phase function calculations, which are difficult for simple-shaped crystals, are essentially not possible at present for these irregular shaped particles. There is evidence from remote measurements of the radiative characteristics at several wavelengths that in some situations a simple geometrical shape may be considered as a sufficient approximation to determine the radiative properties of an ice crystal cloud (Brogniez et al., 1995). The alternative, to get direct in situ measurements of the scattering phase functions, has only recently become possible (Gayet et al., 1997). Figure 4 illustrates two examples obtained during a mountain top cloud experiment using the prototype of a new instrument developed for this purpose, an airborne polar nephelometer (Crépel et al., 


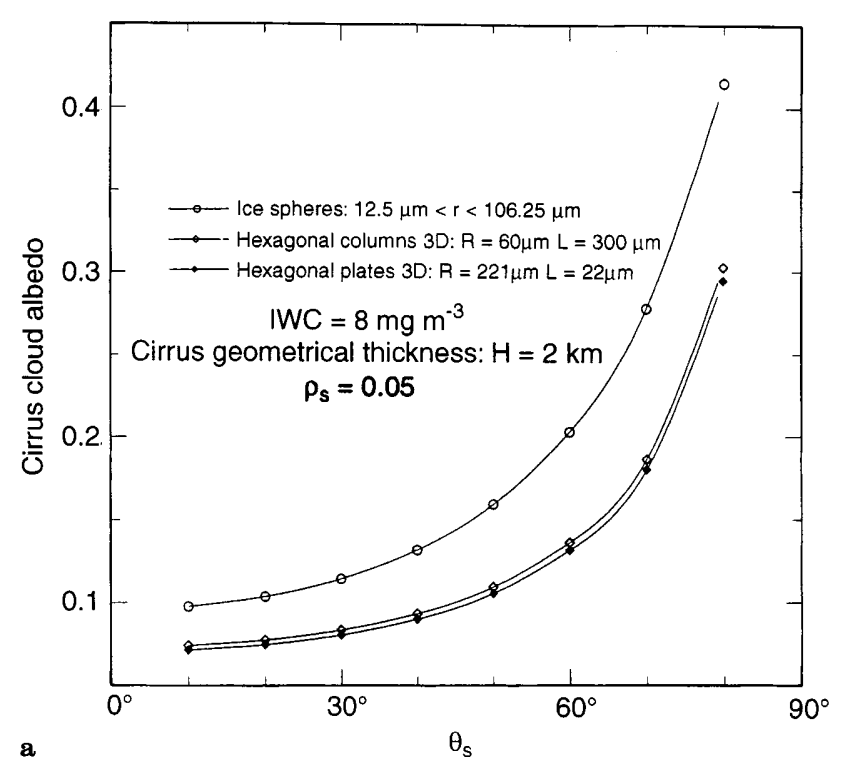

Fig. 3. a Calculated cloud albedos as a function of the solar zenith angle for a cloud geometrical thickness of $2 \mathrm{~km}$, an $I W C$ of $8 \mathrm{mg} \mathrm{m}^{-3}$ and a sea reflectivity $r_{s}=0.05$. Three particle shapes are considered:

1997). The scattering phase function integrated over a small sample of cloud is obtained. One scattering phase function in Fig. 4 is from a cloud of water droplets only and the other from a cloud of ice particles with irregular shapes. The results show that the ice crystals scatter much more light in the side scattering directions (70 to $130^{\circ}$ ) than the cloud droplets. They are much more similar in this respect to the column and plate crystals modelled already than to spheres. The results therefore indicate that cirrus models which assume the ice crystals scatter as though they are spherical particles may induce substantial differences in estimated cloud radiative properties, and emphasise the need for improved

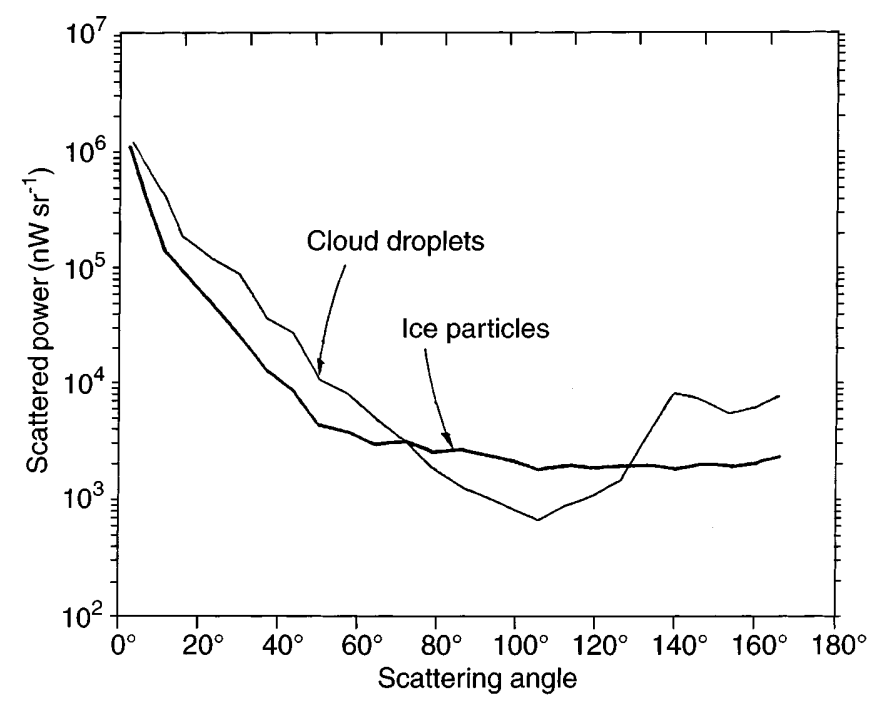

Fig. 4. Examples of scattering phase function measured by the polar nephelometer in the open wind tunnel located at the top of the Puy de Dôme mountain for two typical cloudy conditions: (1) water droplets and (2) ice crystal particles (irregular shaped)

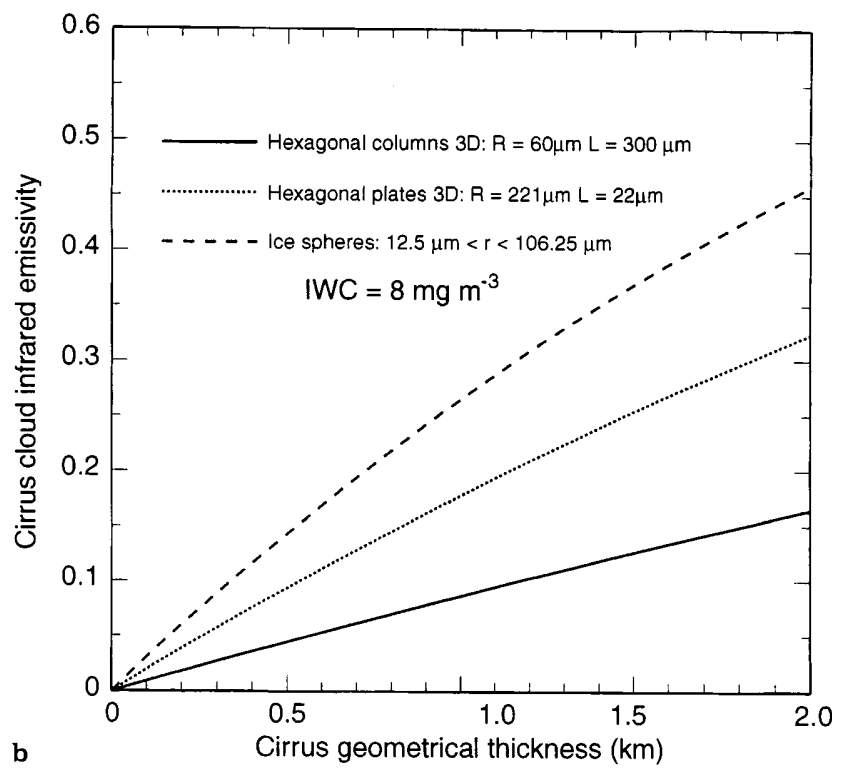

ice sphere, column and plate. b Calculated infra-red emissivity as a function of the cloud geometrical thickness for an $I W C$ of $8 \mathrm{mg} \mathrm{m}^{-3}$. Three particle shapes are considered: ice sphere, column and plate

information on the true scattering phase functions of real cirrus.

\subsection{Small particle shape}

In many studies information on the shape of ice crystals in cirrus comes largely from the $2 \mathrm{D}-\mathrm{C}$ images, and is therefore usually only available for particles larger than $100 \mu \mathrm{m}$ maximum dimension. It is not necessarily reasonable to assume that any small particles will have the same shape as the larger, observable, ones particularly when these are complex. Our experience from the observation of replicas is that the small particles tend to be of relatively simple form, but this result is at present unquantifed. Certainly at larger sizes an increasing complexity with increasing size has been documented in cumuliform ice clouds (Duroure et al., 1994) and a similar effect may be expected in cirrus.

\section{Ice crystal size distribution and cloud radiative properties}

There appear to be many small ice crystals in cirrus clouds, with evidence suggesting that the tops of cirrus (Heymsfield et al., 1990), cirrus at cold temperature (Platt et al., 1989) and contrails (Gayet et al., 1996 b) have the greatest potential for producing small ice crystals (smaller than $50 \mu \mathrm{m}$ ). Ignoring the presence of these particles, because their concentration and radiative properties cannot be quantified with the existing instrumentation, can lead to significant errors in radiative models (Kinne et al., 1992; Takano et al., 1992). Kinne and Liou (1989) illustrated the effect of the size distribution of the crystals by assuming hexagonal ice crystals distributed with two different size spectra, and 
showed that 'small ice' crystals (in their case from 20 to $100 \mu \mathrm{m}$ diameter) dominated the effect of larger particles on the solar albedo. Arnott et al. (1994) showed that small particles can contribute significantly to and sometimes dominate both the solar extinction and the infra-red emission. Yet the cloud radiative properties are usually deduced from the available 2D-C measurements alone (e.g. Heymsfield et al., 1990).

Figure 5 shows a particle size distribution obtained with the 2D-C and FSSP probes during the Interna-

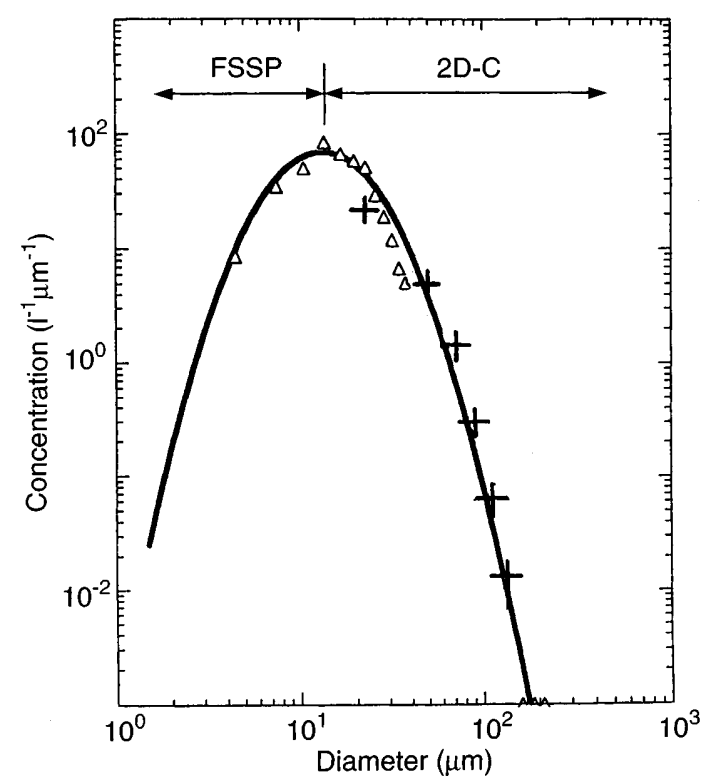

Fig. 5. Distribution of the ice particle size obtained over the North Sea during the ICE experiment. Crosses are relative to the 2D-C probe and triangles to the FSSP probe. The solid curve is the least square polynomial fit used in the radiative calculations

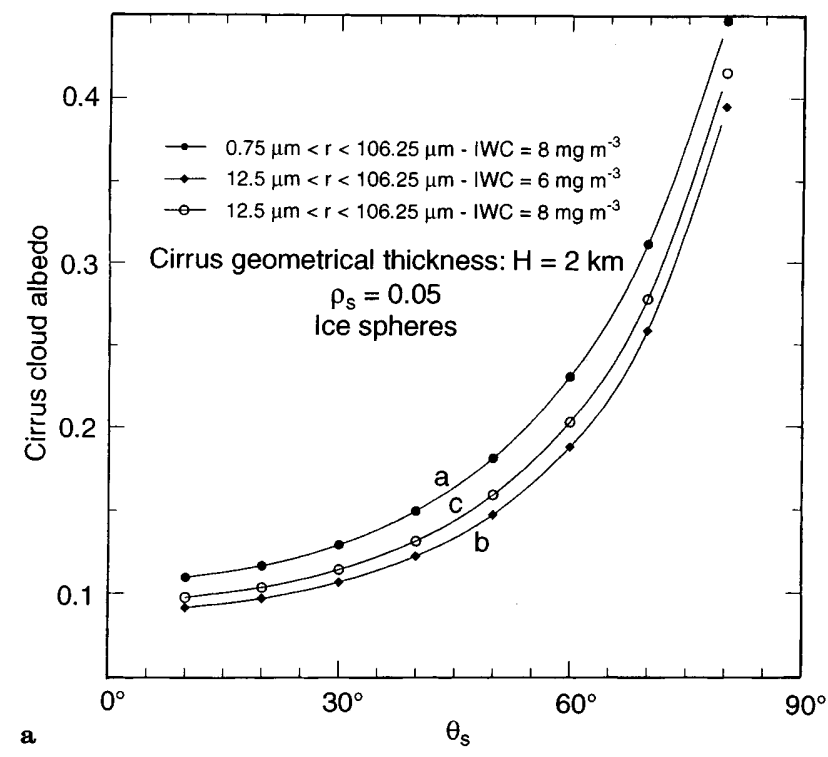

Fig. 6. a Calculated cloud albedos as a function of the solar zenith angle for a cloud geometrical thickness of $2 \mathrm{~km}$ and $r_{s}=0.05$. The curve $a$ refers to the size distribution including the contribution of the small particles $\left(I W C=8 \mathrm{mg} \mathrm{m}^{-3}\right)$, curve $b$ is relative to the truncated size distribution from $12.5 \mathrm{~mm}\left(I W C=6 \mathrm{mg} \mathrm{m}^{-3}\right)$ and curve $c$ refers tional Cirrus Experiment (ICE/EUCREX, Raschke et al., 1990) in contrail-induced cirrus over the North Sea (Gayet et al., 1996b). In this special case the cirrus was apparently formed of quasi-spherical particles and it is possible both to measure the full size distribution down to $3 \mu \mathrm{m}$ diameter with high spatial resolution (because the FSSP is reliable in this special case, see Gayet et al., 1996a) and to model the radiative properties of the particles. The cloud radiative properties have been calculated for three cases: (1) considering the contribution from all particles with diameter larger than $1.5 \mu \mathrm{m}$ (both FSSP and 2D-C measurements), (2) considering the contribution only from particles with diameter larger than $12.5 \mu \mathrm{m}$ (i.e. 2D-C data alone), and (3) considering the contribution only from particles with diameter larger than $12.5 \mu \mathrm{m}$, as for (2), but with the particle concentrations scaled (retaining the same form of the distribution as in Fig. 5) so that the ice water content for this cloud is the same as that for that represented by (1). Case (3) is relevant to the situation where the $I W C$ is independently measured or prescribed by a model rather than being derived from 2D-C measurements. The results of these calculations are shown in Fig. 6a for cloud albedo. Not having data on the small particles present (diameter 1.5 to $12.5 \mu \mathrm{m}$ ) leads to a noticeable decrease in calculated cloud albedo, around $30 \%$ between cases (1) and (2), due to both the radiative properties of small particles and the $I W C$ differences $\left(6 \mathrm{mg} \mathrm{m}^{-3}\right.$ instead of $\left.8 \mathrm{mg} \mathrm{m}^{-3}\right)$. The differences between cases (1) and (3), which are characterized by a same $I W C$, are less (around $20 \%$ ) but highlight the effect of the cloud ice water being distributed into smaller particles.

The sensitivity of the long wave radiative properties of cirrus to the small particles is seen in Fig. 6b, which

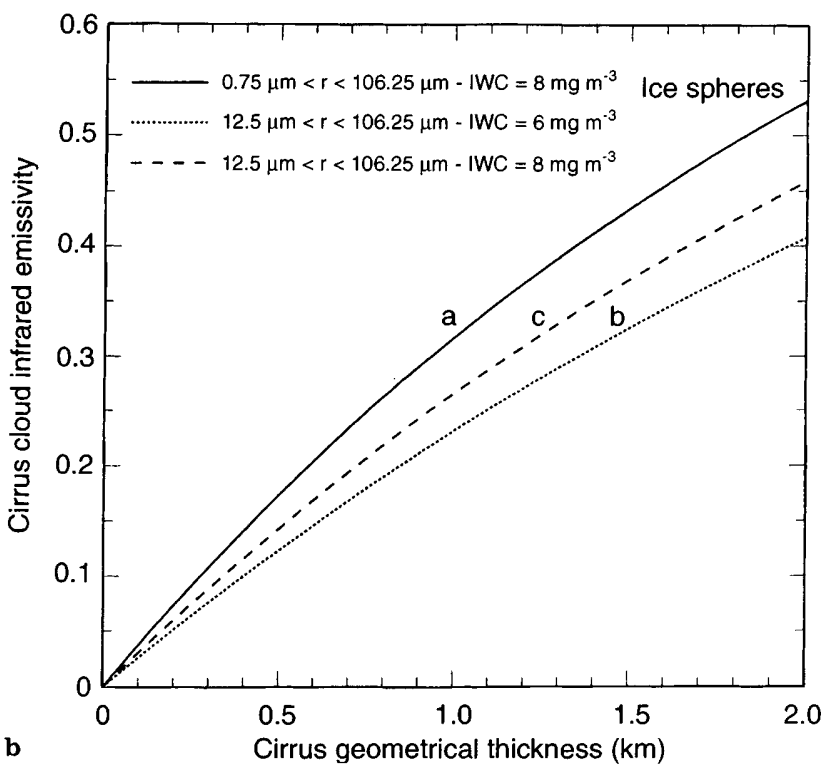

to the truncated size distribution from $12.5 \mathrm{~mm}$ which is weighted in order to have the same $I W C\left(8 \mathrm{mg} \mathrm{m}^{-3}\right)$ as the size distribution including the small particles. b Calculated cloud infra-red emissivity as a function of the geometrical thickness for the three particle distributions considered in Fig. 6a 
shows the infra-red emissivity (at a wavelength of $11 \mu \mathrm{m})$ as a function of the cloud geometrical thickness for the same three particle distributions used in Fig. 6a. For clouds with the same cloud ice water content, cases (1) and (3), there is a noticeable increase (about 20\%) in the infra-red emissivity when the distribution of water substance into the smaller particle sizes is taken into account. As for the short wave properties, the effect of the small particles is more marked (reaching $35 \%$ in the example of Fig. 6b) if their contribution to the ice water content of the cloud is not considered.

\section{Integrated parameters}

The radiative properties of cirrus are frequently expressed in terms of the integrated (bulk, or macrophysical) cloud parameters such as the ice water content $I W C$ and its vertical integral (ice water path), extinction coefficient $(\sigma)$ and effective radius $(R e)$. This is particularly so for the long wave emissivity (Paltridge and Platt, 1981), a sensitive parameter in climate models (Liou, 1986). Ice water contents reported in the literature have been obtained from $2 \mathrm{D}$ probe measurements by integrating the size-spectra. We give quantitative examples of the errors which may arise due to the probe limitations when the radiative properties are expressed in terms of the integrated parameters.

\subsection{Particle concentration}

The differences in measured particle concentration arising from differences between supposedly similar probes, as shown in Fig. 1, can lead to large uncertainties in $I W C$ and $\sigma$ estimates (Gayet et al., 1990). In Fig. 7 (from Gayet et al., 1993) the ice water contents obtained simultaneously by two PMS 2D-C probes (P1, P2) mounted close together on the same aircraft are plotted. The results show that probe P2 overestimates the $I W C$ values by a factor of around 1.8 compared with probe $\mathrm{P} 1$. The visible extinction coefficient profiles estimated from probes $\mathrm{P} 1$ and $\mathrm{P} 2$ during cirrus cloud sampling at different levels (see Fig. 8) appear to be quite different and this leads to discrepancies in visible optical depth values ( $\delta=0.15$ and 0.30 respectively).

Errors from the method of data processing are also reflected in the integrated parameters, the differences in Fig. 2 representing as much as $50 \%$ difference in the $I W C$ estimates.

\subsection{Particle shape}

The $I W C$ determination is also strongly dependent on the particle recognition scheme and on the uncertainties in mass-size relationships (Darlison and Brown, 1988). In cirrus clouds irregular shaped, bullet-rosette and columnar ice particles are all commonly observed. Figure 9 shows a comparison of $I W C$ values obtained using size-to-mass relationships relevant to bullet-ro-

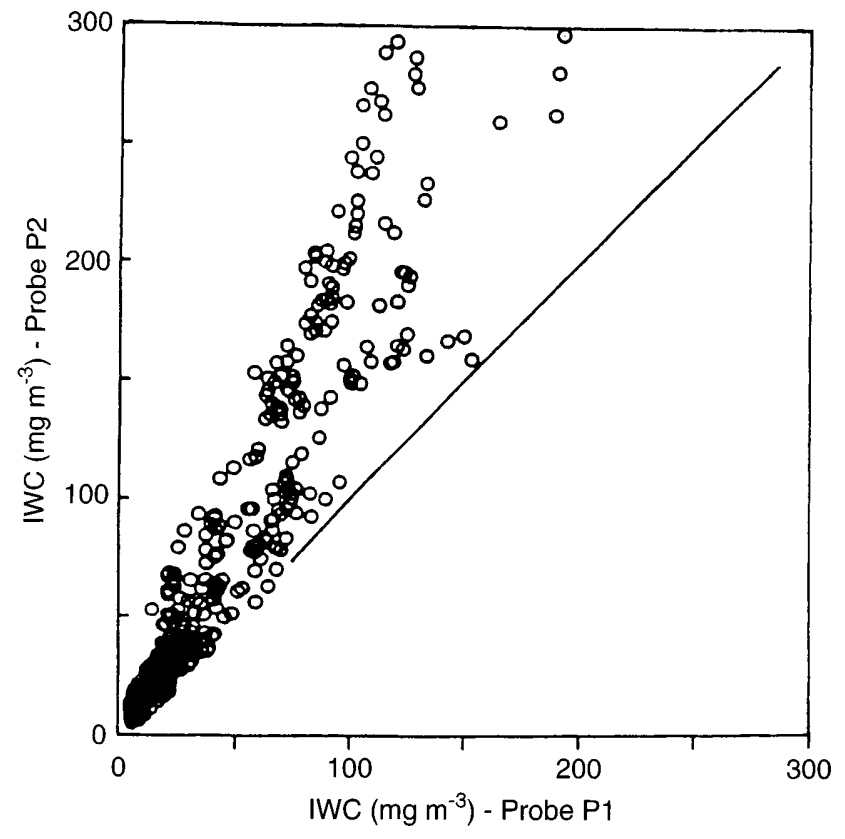

Fig. 7. Comparison of the $I W C$ obtained from two PMS $2 \mathrm{D}-\mathrm{C}$ probes $(\mathrm{P} 1, \mathrm{P} 2)$ mounted close together on the same aircraft (cirrus measurements performed near $-30{ }^{\circ} \mathrm{C}$ during the mission 210 of the International Cirrus Experiment ICE/EUCREX)

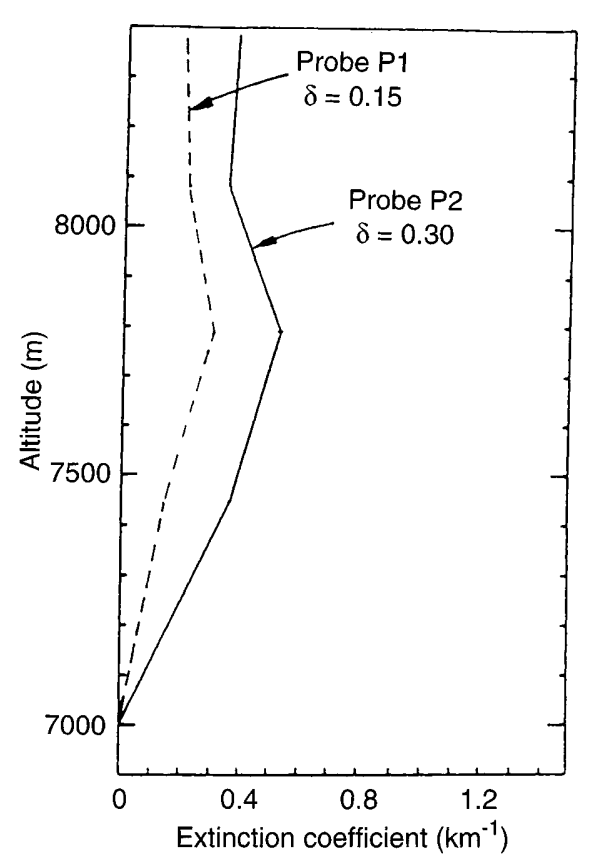

Fig. 8. Vertical profiles of the extinction coefficient at $1.06 \mathrm{~mm}$ deduced from measurements of two PMS 2D-C probes (P1, P2) during the sampling at different levels of a cirrus cloud

settes (labelled R1 on Fig. 9) and irregular particles (R2) respectively. The differences in the $I W C$ estimates are the same order of magnitude as those introduced by the concentration uncertainties discussed already. The subsequent accuracy of $\sigma$ is better because this parameter can be derived from the cross-sectional area $(A)$ of ice particles (see Eq. 2 in Appendix) which is directly measured by the 2D probe (Duroure et al., 1994). 


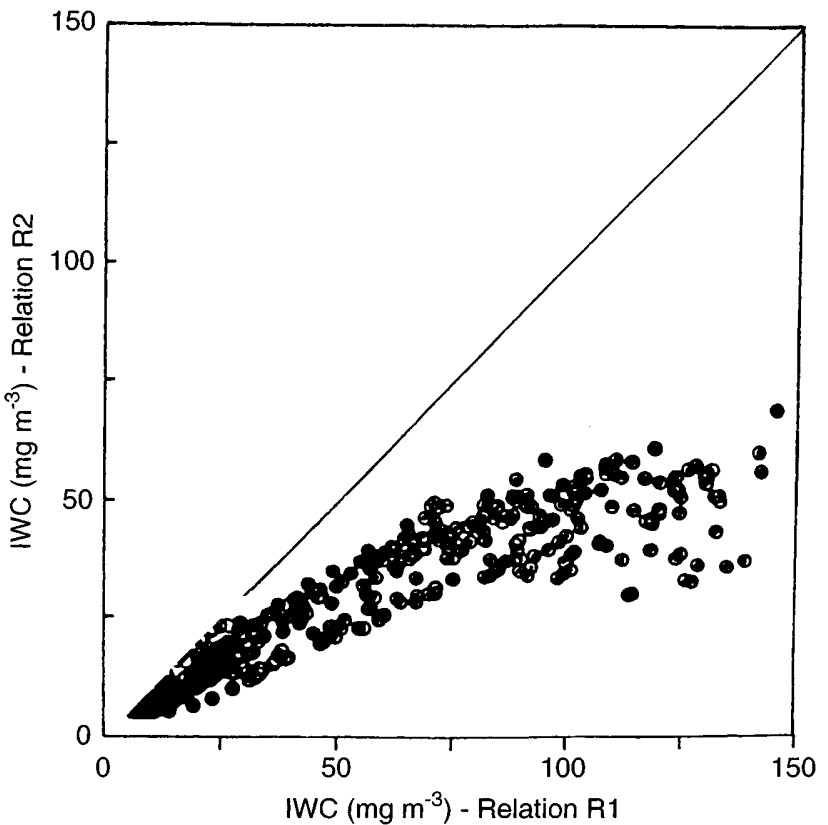

Fig. 9. Comparison of the $I W C$ obtained by using two size-mass relationships ( $R 1$ : bullett-rosette; $R 2$ : irregular) applied to the same data set (cirrus measurements performed near $-30^{\circ} \mathrm{C}$ during the mission 210 of the International Cirrus Experiment ICE/EUCREX)

\subsection{The contribution of small ice crystals to $I W C, \sigma$ and $R_{e}$}

For the special case of the contrail measurements discussed in Sect. 4, the contribution of the small ice crystals to the cloud integrated parameters can be determined. Table 1 gives two sets of cloud parameters calculated from these data, for case (1) (from particles with diameter larger than $12.5 \mu \mathrm{m}$ (i.e. $2 \mathrm{D}-\mathrm{C}$ data alone) and (2) (those from all particles with diameter larger than $1.5 \mu \mathrm{m}$ (both FSSP and 2D-C measurements). Details of the derivation of the parameters are found in the Appendix.

Table 1 shows that merging in the FSSP measurements introduces considerable changes, particularly to the ice particle concentration $\left(730 \mathrm{l}^{-1}\right.$ versus $\left.200 \mathrm{l}^{-1}\right)$ and to the effective radius $(19 \mu \mathrm{m}$ against $26 \mu \mathrm{m})$, and that the $I W C$ increases by around $33 \%$.

Table 1

\begin{tabular}{lrrl}
\hline & 2D-C & \multicolumn{2}{c}{ FSSP $+2 \mathrm{D}-\mathrm{C}$} \\
\hline Particle concentration & 200 & 730 & $\left(1^{-1}\right)$ \\
Effective radius & 26 & 19 & $(\mu \mathrm{m})$ \\
$I W C$ & 6 & 8 & $\left(\mathrm{mg} \mathrm{m}^{-3}\right)$ \\
\hline
\end{tabular}

Fig. 10. a Fraction of $I W C$, $\mathbf{b}$ extinction coefficient $\sigma$ and $\mathbf{c}$ effective radius $R e$ contributed by FSSP to total $I W C, \sigma$ and $R_{e}$ contributed by both FSSP and 2D-C
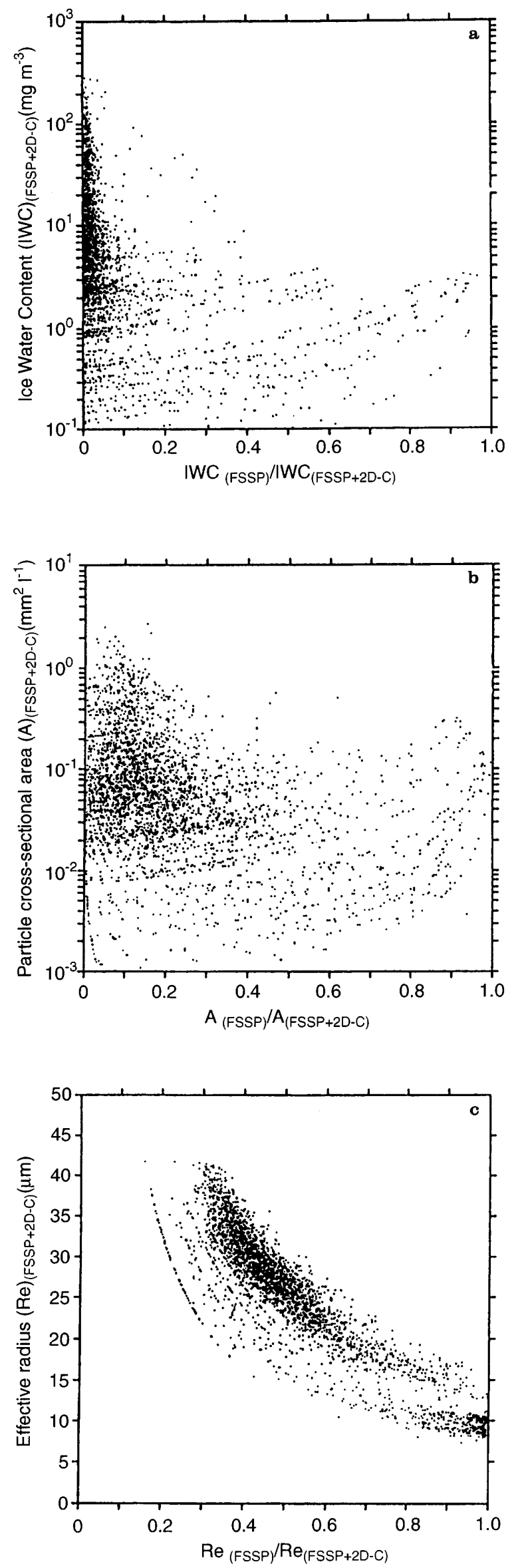
Despite the fact the FSSP-100 is known to overcount when large ice crystals are present (Gardiner and Hallett, 1985; Gayet et al., 1996a), data from this probe is can be used to the estimate when the contribution of particles smaller than $30 \mu \mathrm{m}$ to $I W C, \sigma$ and $R e$ is important. Following the same form of presentation given by Heymsfield and McFarquhar (1996), we show in Fig. 10 the apparent fraction of $I W C, A$ and $R e$ contributed by the data from the FSSP compared to the total $I W C, A$ and $R e$ as calculated using both FSSP and 2D-C data. (Note that $A=\sigma / 2$ in this size range; see Appendix.) Despite the large scatter in the data points, probably due to the natural variability of the clouds, the results give order of magnitude indications of the contribution of particles smaller than $30 \mu \mathrm{m}$ (FSSP). This contribution is significant (greater than 30\%) for $I W C$ and $A$ smaller than about $1 \mathrm{mg} \mathrm{m}^{-3}$ and $10^{-2}$ $\mathrm{mm}^{2} 1^{-1}$ respectively. The results show that the values of the effective $R e$ radius (Fig. 10c) are considerably affected by the contribution of small particles. The contribution remains about $30 \%$ for $R e<35 \mu \mathrm{m}$. These results indicate the approximate mimimum values from which the $2 \mathrm{D}-\mathrm{C}$ estimates may be considered reasonable. The values are the same order as those found by Heymsfield and McFarquhar (1996) in tropical cirrus.

As a consequence of the these uncertainties, an estimate of the accuracy of the $I W C$ determination is problematical in the absence of direct measurement. Data from the evaporative technique described by Nicholls et al. (1990) may be used as a guide to the selection of the most appropriate size-to-mass relationship in 2D data processing (Brown, 1993) and may have some benefit in identifying gross errors in $2 \mathrm{D}$ probe measurements, whether the latter are caused by software or hardware problems. However this technique itself can be invalid in some cases (depending on the calibration and the occurrence of subsatured air). The use of a high performance radar operated simultaneously with instrumented aircraft has also been used for $I W C$ accuracy estimation (Heymsfield and McFarquhar, 1996). The results suggest the probe-derived $I W C$ s are accurate to $\pm 30 \%$ but only when the dimension of the sampled particles is within the PMS probe size range.

\section{Conclusions}

Using examples of data obtained from aircraft measurement flights in mid-latitude cirrus clouds during the EUCREX field observations, we have shown that shortcomings in the usual in situ probes (mainly PMS 2D-C and FSSP-100) can lead to significant errors (exceeding $30 \%$ ) in the estimation of the cloud radiative parameters. These have substantial implications for the use of current data in climate modelling. Attempts are being made to develop new instrumentation to address these difficulties. These new instruments appear to give reliable measurements of small ice crystals and may provide useful complementary measurements for future experiments.
Acknowledgements. This work was supported in France by grants from DGAC $n^{\circ} 9308$, CNRS/PAMOY $n^{\circ} 94 \mathrm{~N} 50 / 0305$ and in New Zealand by FRST contract CO1227 and by internal support from NIWA. It has been done as part of the European Cloud Radiation Experiment (EUCREX) supported by the European Economic Community. The authors are grateful to the anonymous reviewer who gave helpful comments on the content of the manuscript.

The Editor in chief thanks A. Heymsfield for his help in evaluating this paper.

\section{Appendix: derivation of cloud-integrated parameters from PMS probe data}

The integrated parameters of ice water content $(I W C)$, extinction coefficient $(\sigma)$ and effective radius $(R e)$ are obtained from the PMS FSSP and 2D-C probe data using the following relationships:

Ice water content:

$$
\mathrm{IWC}=\pi / 6 \rho_{\mathrm{w}} \sum \mathrm{N}_{\mathrm{i}}\left(\mathrm{D}_{\mathrm{eq}}\right)^{3}
$$

Extinction coefficient:

$\sigma=\sum \mathrm{Q}_{\text {ext }} \mathrm{N}_{\mathrm{i}} \mathrm{A}_{\mathrm{i}}$

Effective radius:

$$
\operatorname{Re}=\pi \sum \mathrm{N}_{\mathrm{i}}\left(0.5 \mathrm{D}_{\mathrm{eq}}\right)^{3} / \sum \mathrm{N}_{\mathrm{i}} \mathrm{A}_{\mathrm{i}}
$$

The parameter $n$ represents the number of size classes of the PMS probe, $N_{i}$ is the size spectrum as a function of the particle area $A_{i}, \rho_{w}$ is the water density, $Q_{\text {ext }}$ is the visible extinction efficiency (assumed to have a value of to 2 over the range of sizes measured, i.e., large particle approximation, valid for particle sizes larger than about $2 \mu \mathrm{m})$ and $D_{e q}$ is the diameter of a water drop which would have the same mass as the crystal of area $A_{i}$. Note that $A_{i}$ is the area of the projected shadow image of the particle. The $D_{e q}-A_{i}$ relationships related to particle habit can be found in Heymsfield (1972).

\section{References}

Arnott W. P., YaYi Dong, and J. Hallett, Role of small ice crystals in radiative properties of cirrus: a case study, FIRE II, November 22, 1991 J. Geophys. Res., 99, 1371-1381, 1994.

Baumgardner, D., Corrections for the response times of particle measuring probes, Sixth Symposium on Meteorological Observations and Instrumentation, 148-151, American Meteorological Society, Boston, Mass., 1987.

Baumgardner, D., J. E. Dye, and W. A. Cooper, The effects of measurement uncertaincies on the analysis of cloud particle data, Proc. 23th Conf. on Radar Meteorol. and Cloud Physics, Snowmass, Co, USA, 313-316, 1986.

Bretherton, F. P., and V. E. Suomi, First International Satellite Cloud Climatology Project Regional Experiment (FIRE) research plan. 76 pp. (Available from the National Climatic Program Office, Rm. 108, 11400 Rockville Pike, Rockville, MD 20852), 1983.

Brogniez, G., Light scattering by finite hexagonal ice crystals arbitrarily oriented in space. Proceedings of the International Radiation Symposium, Lille, France, 18-24 August, 64-67, 1988.

Brogniez, G., J. C. Buriez, V. Giraud, F. Parol, and C. Vanbauce, Determination of effective emittance and radiatively equivalent microphysical model of cirrus from ground-based and satellite 
observations during the International Cirrus Experiment: The 18 October 1989 case study, Mon. Weather Rev., 123, 10251036, 1995.

Brown, P. R. A., Use of holography for airborne cloud physics measurements, J. Atmos. Oceanic Technol., 6, 293-306, 1989.

Brown, P. R. A., Measurements of the ice water content of cirrus using an evaporative technique, J. Atmos. Ocean. Technol., 10, 579-590, 1993.

Cerni, T. A., Determination of the size and concentration of cloud drops with an FSSP, J. Clim. Appl. Meteor., 22, 1346-1355, 1983.

Cooper, W. A., and G. Vali, The origin of ice in mountain cap clouds. J. Atmos. Sci., 38, 1244-1259, 1981

Crépel, O., J-F Gayet, J-F Fournol, and S. Oshchepkov, A new airborne polar nephelometer for the measurements of optical and microphysical cloud properties. Part II: preliminary tests, Annales Geophysicae, 15, 460-470, 1997.

Darlison A. G., and P. R. A. Brown, The use of automatic particle recognition to improve the determination of bulk quantities from PMS 2D probe data in cirrus, Proc. 10th Int. Cloud Physics Conf., Bad Homburg, F.R.G., August 15-20, 1988.

Duroure, C., Une nouvelle methode de traitment des images d'hydrometeores données par les sondes bidemensionelles, J. Rech. Atmos. 16, 71-74, 1982.

Duroure, C., H. R. Larsen, H. Isaka, and P. Personne, 2D image population analysis, J. Rech. Atmos. 34, 195-205, 1994.

Fouilloux A., J. Iaquinta, C. Duroure and F. Albers, 1997: A statistical analysis for pattern recognition of small cloud particles sampled with a PMS-2DC probe. Accepted for publication in Annales Geophysicae, 1997

Gardiner, B. A., and J. Hallett, Degradation of in-cloud forward scattering spectrometer probe in the presence of ice particles, J. Atmos. Ocean. Technol., 2, 171-180, 1985.

Gayet, J-F, P. A. Brown, and F. Albers, Results of the PREICE experiment, 42 pp. Report available from LaMP, Université Blaise Pascal, Clermont-Ferrand, France, 1990.

Gayet, J-F, P. R. A. Brown, and F. Albers, A comparison of incloud measurements obtained with six PMS 2D-C probes, J. Atmos. Ocean. Technol., 10, 180-194, 1993.

Gayet, J-F., G. Febvre, and H. R. Larsen, On the reliability of the PMS FSSP probe in the presence of small ice crystals, J. Atmos. Ocean. Technol., 13, 1300-1310, 1996a.

Gayet, J-F., G. Febvre, G. Brogniez, H. Chepfer, W. Renger, and P. Wendling, Microphysical and optical properties of cirrus and contrails: cloud field study on 13 October 1989, J. Atmos. Sci., 53, 126-138, 1996b.

Gayet, J-F, O. Crépel, J-F. Fournol and S. Oshchepkov, A new airborne polar nephelometer for the measurements of optical and microphysical cloud properties. Part I: Theoretical design, Annales Geophysicae, 15, 451-459, 1997.

Heymsfield, A. J., Ice crystal terminal velocities, J. Atmos. Sci., 29, 1348-1357, 1972.

Heymsfield, A. J., Ice particle evolution in the anvil of a severe thunderstorm during CCOPE J. Atmos. Sci., 43, 2463-2478, 1986.

Heymsfield, A. J., Microphysical structures of stratiform and cirrus clouds in: aerosol cloud-climate interactions, Academic Press, Ed. P. V. Hobbs, 97-121, 1993.

Heymsfield, A. J., and J. Parrish, A computational technique for increasing the effective sampling volume of the PMS twodimensional particle size spectrometer, J. Appl. Meteorol., 17, 1566-1572, 1978.

Heymsfield, A. J., and D. Baumgardner, Summary of a Workshop on processing 2-D probe data, Bull. Am. Meteorol. Soc., 66, $437-440,1985$.

Heymsfield, A. J., and L. M. Miloshevich, Relative humidity and temperature influences on cirrus formation and evolution. Observations from wave clouds and FIRE-II, J. Atmos. Sci., 52, 4302-4326, 1995.

Heymsfield, A. J., and G. M. McFarquhar, High albedos of cirrus in the tropical Pacific warm pool: microphysical interpretations from CEPEX and from Kwajalein, Marshall Islands, J. Atmos. Sci., 53, 2424-2451, 1996.

Heymsfield, A. J., K. M. Miller, and J. D. Spinhirne, The 27-28 October 1986 FIRE IFO Cirrus case study: cloud microstructure, Mon. Weather. Rev., 118, 2313-2328, 1990.

Iaquinta, J., H. Isaka, and P. Personne, Scattering phase function of bullet-rosette ice crystals, J. Atmos. Sci., 42, 1401-1413, 1995.

Kinne, S., and K. N. Liou, The effects of the nonsphericity and size distribution of ice crystals on the radiative properties of cirrus clouds, Atmos. Res., 24, 273-284, 1989.

Kinne, S., T. P. Ackerman, A. J. Heymsfield, F. P. J. Valero, K. Sassen, and J. D. Spinhirne, Cirrus microphysics and radiative transfer: cloud field study on 28 October 1986, Mon. Weather Rev., 20, 661-684, 1992.

Knollenberg, R. G., Three new instruments for cloud physics measurements: the 2-D spectrometer, the forward scattering spectrometer probe and the active scattering aerosol spectrometer, Proc. Int. Conference on Cloud Physics, Boulder, Co., July 26-30, 1976.

Korolev, A. V., S. V. Kusnetsov, Y E. Makarov and V.S. Novikov, Evaluation of measurements of particle size and sample area from optical array probes, J. Atmos. Ocean. Technol., 8, 514522, 1991.

Lawson, R. P., Digital holographic measurements of cloud particles, Proc. AMS Conference on Cloud Physics, Dallas, January $15-20,1995$.

Liou, K. N., Influence of cirrus clouds on weather and climate processes: a global perspective, Mon. Weather Rev., 114, 1167$1199,1986$.

McFarquhar, G. M., and A. J. Heymsfield, Microphysical characteristics of three anvils sampled during the Central Equatorial Experiment, J. Atmos. Sci., 17, 2401-2423, 1996.

Moss, S. J., and D. W. Johnson, Aircraft measurements to validate and improve numerical model parametrizations of the ice to water ratios in clouds, Proc. 11th Int. Conference on Clouds and Precipitation, Montreal, August 17-21, 1992.

Nicolls, S., J. Leighton, and R. Barker, A new fast response instrument for measuring total water content from aircraft, J. Atmos. Ocean. Technol., 7, 706-718, 1990.

Paltridge, C. W. and C. M. R. Platt, Aircraft measurements of solar and infra-red radiation and the microphysics of cirrus clouds, Qu. J. R. Meteorol. Soc., 107, 367-380, 1981.

Platt, C. M. R., J. D. Spinhirne, and W. D. Hart, Optical and microphysical properties of a cold cirrus cloud: evidence for regions of small ice particles, J. Geophys. Res., 94, 151-164, 1989.

Ramanathan, V., E. J. Pitcher, R. C. Malone, and M. L. Blackmon, The response of a spectral general circulation model to refinements in raditive process, J. Atmos. Sci., 40, 605-630, 1983.

Ramanathan, V., R. D. Cess, E. F. Harrison, P. Minnis, B. R. Barkstrom, E. Ahmad, and D. Hartman, Cloud-radiative forcing and climate: results from the Earth Radiation Budget Experiment, Science, 243, 57-63, 1989.

Ramanathan, V., B. Subasilar, G. J. Zhang, W. Conant, R. D. Cess, J. T. Kiehl, H. Grassl, and L. Shi, Warm pool heat budget and shortwave cloud forcing: a missing physics? Science, 267, 499502, 1995.

Raschke, E., European Cloud and Radiation Experiment (EUCREX). Final report on the project EV5V-CT92-0130 EUCREX2, $154 \mathrm{pp}$, available at the GKSS Research Center, Geesthacht, Germany, 1996.

Raschke, E., J. Schmetz, J. Heintzenberg, R. Kandel, and R. Saunders, The International Cirrus Experiment (ICE). A joint European effort, ESA Journal, 14, 193-199, 1990.

Stephens, G. L., S. C. Tsay, P. W. Stackhouse, and P. J. Flatau, The relevance ofthe microphysical and radiative properties of cirrus clouds to climate and climatic feedback, J. Atmos. Sci., 47, 1742-1753, 1990. 
Strauss, B., J. Hallett and P. Wendling, Small crystals in cirrus clouds 7th EUCREX Workshop. 13-15 September 1994, Villeneuve d'Ascq, France. Ed. G. Brogniez, 1995.

Ström, J., and J. Heintzenberg, Water vapor, condensed water and the crystal concentration in orographically influenced cirrus clouds, J. Atmos. Sci., 51, 2368-2383, 1994.

Takano, Y., and K. N. Liou, Radiative transfer in cirrus clouds. Single scattering and optical properties of hexagonal ice crystals, J. Atmos. Sci., 46, 3-20, 1989.

Takano, Y., K. N. Liou, and P. Minnis, The effect of small ice crystals on cirrus infra-red radiative properties, J. Atmos. Sci., 49, 1487-1493, 1992.
Vali, G., M. K. Politovich, D. Baumgardner, and W. A. Cooper, Conduct of cloud spectra measurements Scientific Report 1 to the Air Force Geophysical Laboratory, Contract AFGL-TR79-025, 1980.

World Climate Research Programme, A preliminary cloudless standard atmosphere for radiation computation WCP-112, WMO/TD-24, 1986

Zdunkowski, W. G., R. M. Welch, and G. Korb, An investigation of the structure of typical two-stream methods for the calculation of solar fluxes and heating rates in clouds, Contrib. Atmos. Phys., 53, 147-166, 1980. 